\begin{tabular}{|c|c|c|c|}
\hline \multirow{3}{*}{$\begin{array}{r}\text { Case Reports in } \\
\text { Gastroenterology }\end{array}$} & \multirow{2}{*}{\multicolumn{2}{|c|}{ Case Rep Gastroenterol 2018;12:617-621 }} & \multirow[b]{3}{*}{$\begin{array}{l}\text { Karger } \\
\text { Open'access }\end{array}$} \\
\hline & & & \\
\hline & $\begin{array}{l}\text { DOI: 10.1159/000493922 } \\
\text { Published online: October 17, } 2018\end{array}$ & $\begin{array}{l}\text { (c) } 2018 \text { The Author(s) } \\
\text { Published by S. Karger AG, Basel } \\
\text { www.karger.com/crg }\end{array}$ & \\
\hline & $\begin{array}{l}\text { This article is licensed under the } \\
\text { International License (CC BY-NC) } \\
\text { Usage and distribution for commercia }\end{array}$ & $\begin{array}{l}\text { mons Attribution-NonCommercial } \\
\text { rger.com/Services/OpenAccessLicen } \\
\text { quires written permission. }\end{array}$ & \\
\hline
\end{tabular}

\title{
Severe de novo Ulcerative Colitis following Ixekizumab Therapy
}

\author{
Jobin Philipose ${ }^{\mathrm{a}}$ Moiz Ahmed ${ }^{\mathrm{b}}$ Pretty S. Idiculla ${ }^{\mathrm{c}}$ \\ Stephen M. Mulrooney ${ }^{d}$ Vivek V. Gumaste $^{d}$ \\ aDepartment of Internal Medicine, Staten Island University Hospital, Northwell Health, \\ New York, NY, USA; 'bepartment of Gastroenterology, Mount Sinai School of Medicine, \\ Elmhurst Hospital Center, New York, NY, USA; 'Sree Gokulam Medical College and \\ Research Foundation, Trivandrum, India; ${ }^{d}$ Department of Gastroenterology, Staten Island \\ University Hospital, Northwell Health, New York, NY, USA
}

\section{Keywords}

Ixekizumab $\cdot$ Inflammatory bowel disease $\cdot$ Ulcerative colitis

\section{Abstract}

Ixekizumab is a selective monoclonal antibody targeting interleukin-17A, approved for the treatment of chronic plaque psoriasis. It has rarely been associated with inflammatory bowel disease (IBD) in randomized trials only. We report a unique case of severe new-onset ulcerative colitis in a young male complicated by cytomegalovirus infection who was on ixekizumab therapy for plaque psoriasis. We recommend that clinicians should exercise caution before prescribing ixekizumab as it seems to induce and exacerbate IBD.

\section{Introduction}

Biologics have revolutionized the treatment of various immune diseases. Ixekizumab, a biological agent, is a selective monoclonal antibody inhibitor targeting interleukin-17A (IL17A), approved for the treatment of chronic plaque psoriasis, psoriatic arthritis, and ankylosing spondylitis. The role of IL-17 in inflammatory bowel disease (IBD) has remained controversial, with murine models suggesting a protective role against IBD and human studies 
showing no efficacy of IL 17 antagonists against Crohn's disease (CD) or in some case worsening of $\mathrm{CD}[1-3]$.

Phase III trials with ixekizumab have shown the potential adverse effect of new-onset CD and ulcerative colitis (UC) among exposed patients [4]. However, this number remains low. We present a unique real-world scenario of new-onset UC complicated with Clostridium difficile and cytomegalovirus (CMV) colitis in a young patient who was on ixekizumab therapy for the treatment of plaque psoriasis.

\section{Case Report}

A 31-year-old male presented to the emergency department complaining of abdominal pain and bloody diarrhea of 3 weeks' duration. He was in his usual state of health until 3 weeks before admission, when he started developing diffuse severe colicky abdominal pain. The pain was followed by over 5 episodes of diarrhea per day with streaks of blood, accompanied by weight loss, tenesmus, and chills. The patient did not report any previous similar episodes. His only medical history includes chronic plaque psoriasis; he was started on ixekizumab therapy 3 months prior to presentation and currently his symptoms are well controlled. There were no other relevant hospitalizations and home medications.

He has no family history of IBD and reports a 10 pack-years smoking history during his lifetime. He denies any blood transfusions, recent travel or high-risk sexual behavior in the past.

On presentation, the patient was hemodynamically stable and afebrile. His physical examination was significant for left lower quadrant tenderness with no rebound or guarding. His initial laboratory results revealed a white cell count of $14,000 / \mathrm{mm}^{3}$ (granulocytes $67 \%$, lymphocytes $19 \%$, monocytes $10 \%$ ), hemoglobin $14.8 \mathrm{~g} / \mathrm{dL}$, platelets $359 / \mathrm{mm}^{3}$, albumin 3.9 $\mathrm{g} / \mathrm{dL}$, ESR $69 \mathrm{~mm} / \mathrm{h}$, and CRP $71.1 \mathrm{mg} / \mathrm{L}$. Liver profile, HIV, hepatitis panel, and ANCA serology were unremarkable. Stool testing showed many white cells, although cultures were negative for pathogens including nucleic acid amplification test, enzyme immunoassay for $C$. difficile toxin A and B. A computed tomographic scan of his abdomen with intravenous contrast demonstrated pancolitis with no drainable fluid collection. Initial flexible sigmoidoscopy revealed an absent vascular pattern, erythematous friable mucosa with spontaneous bleeding, and severe ulcerative proctosigmoiditis (Fig. 1). Colonic biopsy obtained from the ulcers revealed chronic lymphoplasmacytic infiltration (Fig. 2). All these features in the above setting were consistent with the diagnosis of new-onset UC (Mayo Score 12).

The patient was started on oral mesalamine ( $4 \mathrm{~g} /$ day), intravenous methylprednisolone (60 mg/day), and parenteral fluids. After 2 weeks of hospitalization, he developed $C$. difficile infection and oral vancomycin $125 \mathrm{mg}$ orally was given for a total of 10 days. Initially, he showed mild improvement; however, 2 weeks later, bloody diarrhea recurred with worsening abdominal pain and anorexia. He had a 10-pound weight loss since admission, along with severe hypoalbuminemia of $2.6 \mathrm{~g} / \mathrm{dL}$ and hemoglobin dropped to $7.1 \mathrm{~g} / \mathrm{dL}$. He was started on total parenteral nutrition, also requiring 1 unit of packed red blood cells. A repeat flexible sigmoidoscopy at this point illustrated worsening erosions and deep ulcers with heaped-up margins. Repeat biopsy from the ulcers was positive for CMV inclusion bodies. His CMV PCR DNA level was $426 \mathrm{IU} / \mathrm{mL}$ (reference range $<200 \mathrm{IU} / \mathrm{mL}$ ). Thus, establishing the diagnosis of steroid-refractory UC with superimposed CMV colitis. It is possible that the patient had a reactivation of latent CMV infection or acquiring an exogenous strain secondary to immunosuppression by glucocorticoids. 
After screening for hepatitis B and latent tuberculosis, the patient was started on an induction therapy with infliximab infusion $(5 \mathrm{mg} / \mathrm{kg}$ ) for UC and simultaneously treated for CMV colitis with intravenous ganciclovir (5 mg/kg every $12 \mathrm{~h}$ ). After 1 week, he experienced significant clinical improvement, tolerating oral diet, bowel movement less than 3 per day, and not requiring further blood transfusions. He was discharged on oral valganciclovir for 3 weeks and infliximab infusion every 8 weeks. Currently, the patient is in remission after 6 months and ixekizumab was stopped for his plaque psoriasis after consulting his dermatologist.

\section{Discussion}

Therapy for IBD has evolved since the introduction of anti-tumor necrosis factor (antiTNF) antibody. Many therapeutic agents aimed at inhibition of proinflammatory cytokines (TNF- $\alpha$, IL-6, IL-13, IL-17, IL-18, and IL-21) or supporting the action of anti-inflammatory cytokines have been evaluated for IBD. Some studies have reported that IL-17 is a paramount proinflammatory cytokine expressed in IBD patients and colitis mice $[5,6]$. In contrast, a protective function of IL-17 in T-cell-mediated intestinal inflammation was demonstrated in other studies [7]. These complex molecular pathways still need further elucidation, as in the case of secukinumab (anti-IL-17 antibody) that unexpectedly resulted in worsening of CD among treated patients [2]. Similarly, evaluating data from 7 ixekizumab trials conducted in the past, overall 19 patients were considered to have definite or probable IBD out of 4,209 treated [8]. Further, only 12 patients were reported to have UC.

It is a well-known fact that psoriasis patients have an increased prevalence of IBD $[9,10]$. One study reported that patients with psoriasis were 1.6 times more likely to have UC [11]. Both psoriasis and IBD are inflammatory disorders and they seem to share similar immunepathogenetic mechanisms: firstly, the involvement of the same chromosomal loci $6 \mathrm{p} 22,16 \mathrm{q}$, $1 \mathrm{p} 31$, and $5 \mathrm{q} 33$, which is crucial to innate and adaptive immunity; and secondly, T-regulatory cells, T-helper 17, and IL-17A, and IL-22 are considered to have a key role in the pathogenetic process in both these diseases. So, it is possible that ixekizumab may trigger a flare of previously undiagnosed IBD in psoriasis.

In our case, the patient had no previous symptoms or family history of IBD, so we conclude that he developed de novo UC. He did not show improvement with conventional steroids, hence requiring biological therapy with infliximab infusion. In view of his condition, ixekizumab was stopped completely, and no relapse was reported after 6 months, further supporting our diagnosis of drug-induced UC.

In conclusion, ixekizumab seems to induce and exacerbate IBD. Physicians should be vigilant before prescribing this medication. Patients on ixekizumab should be monitored aggressively for symptoms suggestive of IBD to avoid delay in diagnosis and management, thereby preventing catastrophic outcomes.

\section{Statement of Ethics}

Approval from the ethics committee was not required for this case report. Informed consent was obtained from the patient for publication of this case report and any accompanying images. 


\section{Disclosure Statement}

None of the authors has any financial conflicts of interest to declare.

\section{Author Contributions}

Jobin Philipose, MD: Patient management, writing the manuscript, literature research, article guarantor.

Moiz Ahmed, MD: Literature research, editing the manuscript.

Pretty S. Idiculla: Literature research, editing the manuscript.

Stephen M. Mulrooney, MD: Management of the case, critical revision of the manuscript. Vivek V. Gumaste, MD: Study mentor, final approval of the manuscript to be submitted.

\section{References}

1 O'Connor W Jr, Kamanaka M, Booth CJ, Town T, Nakae S, Iwakura Y, et al. A protective function for interleukin 17A in T cell-mediated intestinal inflammation. Nat Immunol. 2009 Jun;10(6):603-9.

2 Hueber W, Sands BE, Lewitzky S, Vandemeulebroecke M, Reinisch W, Higgins PD, et al.; Secukinumab in Crohn's Disease Study Group. Secukinumab, a human anti-IL-17A monoclonal antibody, for moderate to severe Crohn's disease: unexpected results of a randomised, double-blind placebo-controlled trial. Gut. 2012 Dec;61(12):1693-700.

3 Targan SR, Feagan B, Vermeire S, Panaccione R, Melmed GY, Landers C, et al. A randomized, double-blind, placebo-controlled study of brodalumab in patients with moderate-to-severe Crohn's disease. Am J Gastroenterol. 2016 Nov;111(11):1599-607.

4 Gordon KB, Colombel JF, Hardin DS. Phase 3 Trials of Ixekizumab in Moderate-to-Severe Plaque Psoriasis. N Engl J Med. 2016 Nov;375(21):2102.

5 Owaga E, Hsieh RH, Mugendi B, Masuku S, Shih CK, Chang JS. Th17 cells as potential probiotic therapeutic targets in inflammatory bowel diseases. Int J Mol Sci. 2015 Sep;16(9):20841-58.

6 Chen L, Zou Y, Peng J, et al. Lactobacillus acidophilus suppresses colitis-associated activation of the IL23/Th17 axis. J Immunol Res. 2015;2015:909514.

7 Strzępa A, Szczepanik M. IL-17-expressing cells as a potential therapeutic target for treatment of immunological disorders. Pharmacol Rep. 2011;63(1):30-44.

8 Reich K, Leonardi C, Langley RG, Warren RB, Bachelez H, Romiti R, et al. Inflammatory bowel disease among patients with psoriasis treated with ixekizumab: A presentation of adjudicated data from an integrated database of 7 randomized controlled and uncontrolled trials J Am Acad Dermatol. 2017 Mar;76(3):441448.e2.

9 Skroza N, Proietti I, Pampena R, La Viola G, Bernardini N, Nicolucci F, et al. Correlations between psoriasis and inflammatory bowel diseases. BioMed Res Int. 2013;2013:983902.

10 Ouyang W, Kolls JK, Zheng Y. The biological functions of T helper 17 cell effector cytokines in inflammation. Immunity. 2008 Apr;28(4):454-67.

11 Christophers E. Comorbidities in psoriasis. Clin Dermatol. 2007 Nov-Dec;25(6):529-34. 


\section{Case Reports in Gastroenterology}
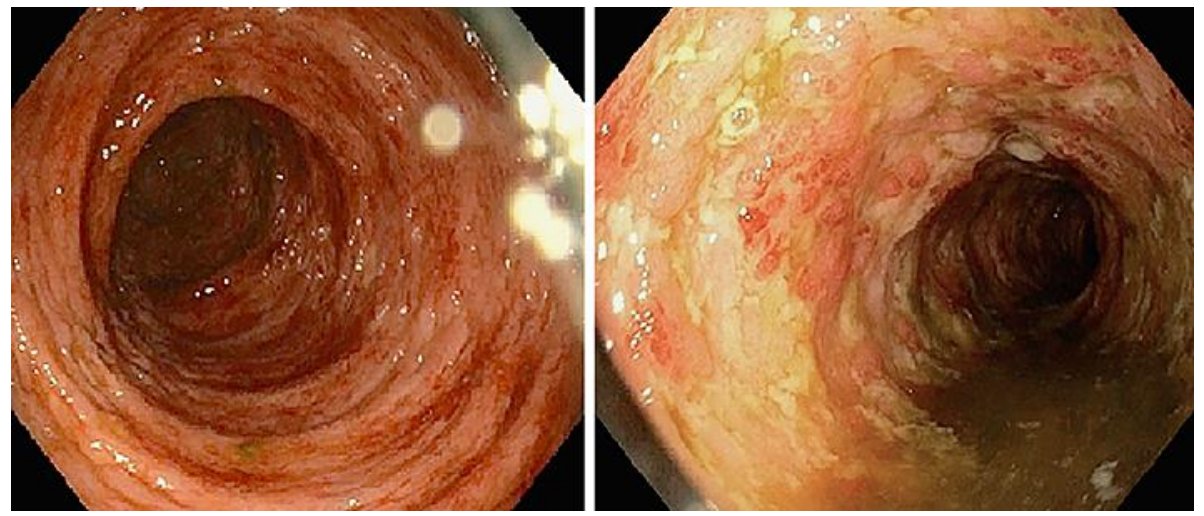

Fig. 1. Initial endoscopic evaluation showing severe colitis throughout the colon.

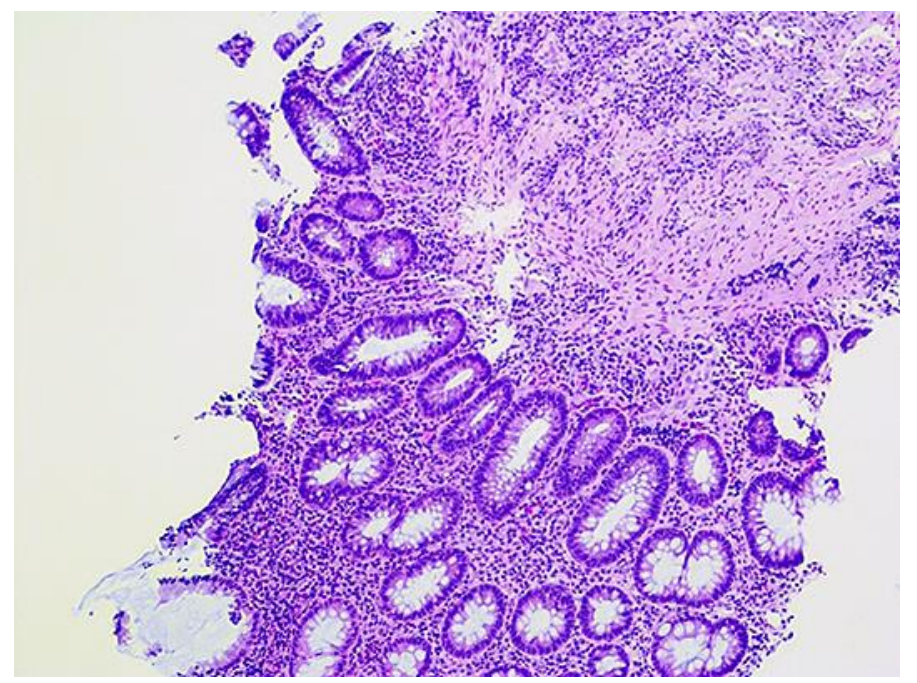

Fig. 2. The colonic biopsy reveals chronic active inflammation (H\&E stain, original magnification, $\times 100$ ). 